Check for updates

Cite this: Sustainable Energy Fuels, 2019, 3, 2819

Received 10th July 2019

Accepted 12th August 2019

DOI: $10.1039 / c 9 s e 00486 f$

rsc.li/sustainable-energy

\title{
Controlling the strength of interaction between carbon dioxide and nitrogen-rich carbon materials by molecular design $\uparrow$
}

\author{
Ralf Walczak, ${ }^{a}$ Aleksandr Savateev, (D) ${ }^{a}$ Julian Heske, ${ }^{b}$ Nadezda V. Tarakina, (D) a \\ Sudhir Sahoo, ${ }^{c}$ Jan D. Epping, ${ }^{c}$ Thomas D. Kühne, ${ }^{b}$ Bogdan Kurpil, ${ }^{a}$ \\ Markus Antonietti iD a and Martin Oschatz iD *ad
}

\begin{abstract}
Thermal treatment of hexaazatriphenylene-hexacarbonitrile (HAT-CN) in the temperature range from $500{ }^{\circ} \mathrm{C}$ to $700{ }^{\circ} \mathrm{C}$ leads to precise control over the degree of condensation, and thus atomic construction and porosity of the resulting $\mathrm{C}_{2} \mathrm{~N}$-type materials. Depending on the condensation temperature of HAT-CN, nitrogen contents of more than 30 at\% can be reached. In general, these carbons show adsorption properties which are comparable to those known for zeolites but their pore size can be adjusted over a wider range. At condensation temperatures of $525^{\circ} \mathrm{C}$ and below, the uptake of nitrogen gas remains negligible due to size exclusion, but the internal pores are large and polarizing enough that $\mathrm{CO}_{2}$ can still adsorb on part of the internal surface. This leads to surprisingly high $\mathrm{CO}_{2}$ adsorption capacities and isosteric heat of adsorption of up to $52 \mathrm{~kJ} \mathrm{~mol}^{-1}$. Theoretical calculations show that this high binding enthalpy arises from collective stabilization effects from the nitrogen atoms in the $\mathrm{C}_{2} \mathrm{~N}$ layers surrounding the carbon atom in the $\mathrm{CO}_{2}$ molecule and from the electron acceptor properties of the carbon atoms from $\mathrm{C}_{2} \mathrm{~N}$ which are in close proximity to the oxygen atoms in $\mathrm{CO}_{2}$. $\mathrm{A}$ true $\mathrm{CO}_{2}$ molecular sieving effect is achieved for the first time in such a metal-free organic material with zeolite-like properties, showing an IAST $\mathrm{CO}_{2} / \mathrm{N}_{2}$ selectivity of up to 121 at $298 \mathrm{~K}$ and a $\mathrm{N}_{2} / \mathrm{CO}_{2}$ ratio of $90 / 10$ without notable changes in the $\mathrm{CO}_{2}$ adsorption properities over 80 cycles.
\end{abstract}

\section{Introduction}

Due to the rapid increase of the $\mathrm{CO}_{2}$ level in the atmosphere and the problems associated with this, selective $\mathrm{CO}_{2}$ capture from air or from point sources of emission (e.g., coal-fired power plants) is intensively studied..$^{\mathbf{1 - 4}}$ Chemical absorption of $\mathrm{CO}_{2}$ in dissolved amines ("scrubbing") is the industrially established technique for $\mathrm{CO}_{2}$ capture from power plant exhaust as it is very selective due to covalent carbamate bond formation. Chemisorption of $\mathrm{CO}_{2}$ on amines immobilized on solid surfaces can even be applied for selective $\mathrm{CO}_{2}$ capture from air, that is, at very low partial pressure. ${ }^{2}$ Due to the high binding enthalpy of $\mathrm{CO}_{2}$, these methods suffer from high energy penalty during

${ }^{a}$ Max Planck Institute of Colloids and Interfaces, Colloid Chemistry, Research Campus Golm, Am Mühlenberg 1,D-14476 Potsdam, Germany.E-mail: martin.oschatz@ mpikg.mpg.de

${ }^{b}$ Chair of Theoretical Chemistry and Center for Sustainable Systems Design, University of Paderborn, Warburger Str. 100, D-33098 Paderborn, Germany

${ }^{c}$ Fakultät II: Mathematik \& Naturwissenschaften, Institut für Chemie, Technische Universität Berlin, Hardenbergstr. 40, 10623 Berlin, Germany

${ }^{d}$ Institute of Chemistry, University of Potsdam, Karl-Liebknecht-Str. 24-25, D-14476 Potsdam, Germany

$\dagger$ Electronic supplementary information (ESI) available. See DOI: 10.1039/c9se00486f regeneration. ${ }^{5-7}$ Physical adsorption (physisorption) of $\mathrm{CO}_{2}$ with lower binding enthalpy (in the range of van der Waals forces) is an alternative with less energy intensive regeneration. Great research efforts have been made recently and more and more nanomaterials for selective $\mathrm{CO}_{2}$ capture have been proposed..$^{8-10}$

Typical physical adsorbents applied are nanoporous materials such as zeolites or zeolitic imidazole frameworks, ${ }^{\mathbf{1 1 - 1 5}}$ carbon-based materials, ${ }^{16-21}$ porous organic frameworks, ${ }^{22,23}$ and metal-organic-frameworks (MOFs) ${ }^{24-27}$ Common methods to increase their affinity towards $\mathrm{CO}_{2}$ (that is, the $\mathrm{CO}_{2}$ adsorption enthalpy) include the introduction of specific interaction sites (e.g., basic nitrogen sites/or extra framework cations in porous carbons or amine MOFs), ${ }^{28-33}$ as well as the tuning of the ultramicroporosity of the sorbents. ${ }^{\mathbf{1 8 , 3 4 , 3 5}}$ Some thermodynamic sweet spots have been found for different families of materials, often inspired by mimicking nature's highly selective $\mathrm{CO}_{2}$ capture mechanism in the ribulose-1,5-bisphosphate carboxylase/oxygenase (Rubisco). ${ }^{36}$ However, as long as high $\mathrm{CO}_{2} / \mathrm{N}_{2}$ selectivity is the target, these attempts suffer from one or more of the following problems: (i) the quadrupole moment $\left(13.4 \times 10^{-40} \mathrm{C} \mathrm{m}^{2}\right)$ and polarizability $\left(26.3 \times 10^{-25} \mathrm{~cm}^{3}\right)$ of $\mathrm{CO}_{2}$ are indeed higher than for $\mathrm{N}_{2}\left(4.7 \times 10^{-40} \mathrm{C} \mathrm{m}^{2}\right.$ and $17.6 \times$ $10^{-25} \mathrm{~cm}^{3}$ ), but it should be kept in mind that any attempt to increase $\mathrm{CO}_{2}$ selectivity by introducing specific binding sites 
will also increase the binding enthalpy of the adsorbent towards $\mathrm{N}_{2}$; (ii) every porous material with a high porosity for nitrogen will always suffer from significant contribution of less discriminative van der Waals interaction; (iii) many of the record-holders in terms of selectivity for atmospheric $\mathrm{CO}_{2}$ capture suffer from limited stability under wet conditions, are difficult to be synthesized, and often contain metals.

Although the promise of kinetic size exclusion of $\mathrm{N}_{2}$ (kinetic diameter: $0.36 \mathrm{~nm}$ ) over $\mathrm{CO}_{2}$ (kinetic diameter: $0.33 \mathrm{~nm}$ ) to enhance $\mathrm{CO}_{2} / \mathrm{N}_{2}$ selectivity of physically adsorbing materials is generally accepted ${ }^{34,37}$ and although it is obvious that $\mathrm{CO}_{2} / \mathrm{N}_{2}$ selectivity increases significantly at lower available $\mathrm{N}_{2}$ surface area, ${ }^{8}$ a real molecular $\mathrm{CO}_{2}$ sieving adsorbent has not yet been reported. The likely reason is that a decrease of the "pore size" of the adsorbents down to the molecular dimensions of $\mathrm{CO}_{2}$ leads to a significant activation barrier for adsorption, or in other words, $\mathrm{CO}_{2}$ adsorption in such narrow spaces is kinetically hindered. The only way to overcome this limitation seems to be the development of adsorbent materials with higher chemical affinity towards $\mathrm{CO}_{2}$. It is not surprising that materials with "ionic character" (i.e., materials that contain Coulomb charges in their structure as does Rubisco) such as metalorganic materials and zeolites have already been successfully utilized for $\mathrm{CO}_{2} / \mathrm{N}_{2}$ separation at outstanding selectivity. ${ }^{\mathbf{3 8 - 4 0}}$

In contrast to such crystalline materials with defined pore size, carbon-based materials instead show narrow pores with a distribution of sizes, but their mean size can in principle be sleeplessly adjusted. For the separation of small molecules like $\mathrm{N}_{2}$ and $\mathrm{CO}_{2}$, carbon materials still lack the combination of narrow porosity and high polarizability towards $\mathrm{CO}_{2}$. We have recently reported that simple thermal condensation of hexaazatriphenylene-hexacarbonitrile (HAT-CN) molecules results in the formation of nitrogen-rich HAT-CN-derived carbon materials with high structural microporosity and a near-perfect $\mathrm{C}_{2} \mathrm{~N}$-type composition. Porosity and nitrogen content can be adjusted by the synthesis temperature. The high heteroatom doping level with well-defined structure motives introduced from the pre-organized precursor and the narrow micropores lead to zeolite-like adsorption properties of these $\mathrm{C}_{2} \mathrm{~N}$ materials. ${ }^{20,41}$

We further utilize this concept and realize a $\mathrm{CO}_{2} / \mathrm{N}_{2}$ molecular sieve effect by only partially condensing HAT-CN at temperatures below $550{ }^{\circ} \mathrm{C}$. Synthesis at $525{ }^{\circ} \mathrm{C}$ leads to nitrogen-rich carbon materials with porosity that is still partly accessible for reversible $\mathrm{CO}_{2}$ adsorption but the material shows no notable uptake of $\mathrm{N}_{2}$. To the best of our knowledge, that is the first time, a metal-free carbon-based material with such narrow pores has been used for $\mathrm{CO}_{2}$ molecular sieving working on a reasonable timescale.

\section{Experimental details}

\section{Materials synthesis}

The synthesis of hexaazatriphenylene-hexacarbonitrile (HAT$\mathrm{CN})$ was carried out according to a previously described procedure. ${ }^{42}$ Hexaketocyclohexane octahydrate (4 g, $\left.12.6 \mathrm{mmol}\right)$ and diaminomaleonitrile $(10.88 \mathrm{~g}, 100.8 \mathrm{mmol})$ were refluxed in acetic acid (AcOH, $150 \mathrm{~mL}$ ) for $2 \mathrm{~h}$. The black suspension was filtered off while hot and washed with hot AcOH $(3 \times 25 \mathrm{~mL})$ resulting in a black solid. The solid was suspended in $30 \%$ $\mathrm{HNO}_{3}(60 \mathrm{~mL})$ and heated at $100{ }^{\circ} \mathrm{C}$ for $3 \mathrm{~h}$. The hot dark brown suspension was poured into ice water $(200 \mathrm{~mL})$ and cooled overnight. The suspension was filtered and the solid was refluxed in $\mathrm{MeCN}$ ( $400 \mathrm{~mL}$ ) for $2 \mathrm{~h}$ and was filtered. The filtrate was dried under vacuum to give an orange solid $(2.4 \mathrm{~g}$, yield $50 \%) .{ }^{13} \mathrm{C}$ NMR (DMSO- $\left.d_{6}, 100 \mathrm{MHz}\right): \delta 142.0,135.8,114.5$.

Nitrogen-rich carbons (C-HAT-CN- $X$ materials) were prepared using HAT-CN (500 $\mathrm{mg}$ ) for carbonization in a horizontal tubular furnace at different temperatures for $1 \mathrm{~h}$ under $\mathrm{N}_{2}$ gas flow. The heating ramp was $2{ }^{\circ} \mathrm{C} \min ^{-1}$ from room temperature to $80{ }^{\circ} \mathrm{C}$ and $4{ }^{\circ} \mathrm{C} \min ^{-1}$ from $80{ }^{\circ} \mathrm{C}$ to the maximum temperature $\left(500{ }^{\circ} \mathrm{C}, 525{ }^{\circ} \mathrm{C}, 550{ }^{\circ} \mathrm{C}\right.$, or $\left.700{ }^{\circ} \mathrm{C}\right)$. The condensed materials are labelled as C-HAT-CN- $X$, where $X$ represents the synthesis temperature.

\section{Materials characterization}

Prior to all physisorption measurements, the samples were degassed under vacuum at $200{ }^{\circ} \mathrm{C}$ for $20 \mathrm{~h}$. $\mathrm{Ar}, \mathrm{CO}_{2}, \mathrm{~N}_{2}$, and $\mathrm{H}_{2} \mathrm{O}$ vapor physisorption were performed on a Autosorb IQ apparatus (Quantachrome Instruments). Low pressure physisorption measurements were performed using Ar at $-186{ }^{\circ} \mathrm{C}$ with $\sim 20 \mathrm{mg}$ of sample. The pore size distributions were calculated using the quenched solid density functional theory (QSDFT) method (adsorption branch kernel) for Ar adsorbed on carbon with cylindrical/sphere pore shape at $87 \mathrm{~K}$, integrated into the ASiQwin 3.0 analysis software. The specific surface areas (SSAs) were calculated using the multi-point Brunauer-Emmett-Teller (BET) model $\left(p p_{0}{ }^{-1}=0.005-0.05\right)$. Total pore volumes $\left(V_{\text {total }}\right)$ were determined at $p p_{0}{ }^{-1}=0.95 . \mathrm{CO}_{2}\left(0^{\circ} \mathrm{C}\right.$ and $\left.25^{\circ} \mathrm{C}\right), \mathrm{N}_{2}$ $\left(-196{ }^{\circ} \mathrm{C}, 0{ }^{\circ} \mathrm{C}\right.$, and $\left.25{ }^{\circ} \mathrm{C}\right)$, and $\mathrm{H}_{2} \mathrm{O}\left(25{ }^{\circ} \mathrm{C}\right)$ physisorption measurements were carried out with $40-50 \mathrm{mg}$ of sample at the same instrument. The isosteric heat of $\mathrm{CO}_{2}$ adsorption was obtained based on the Clausius-Clapeyron equation using an option integrated in the ASiQwin 3.0 analysis software (Quantachrome Instruments).

The determination of $\mathrm{CO}_{2}$ over $\mathrm{N}_{2}$ selectivity $(S)$ (at $298 \mathrm{~K}$; for $\mathrm{N}_{2} / \mathrm{CO}_{2}$ ratio of 90/10) followed the ideal adsorption solution theory (IAST) method $^{43}$ and was calculated using following equation:

$$
S_{\mathrm{CO}_{2} / \mathrm{N}_{2}}=X_{\mathrm{CO}_{2}} / X_{\mathrm{N}_{2}} \times Y_{\mathrm{N}_{2}} / Y_{\mathrm{CO}_{2}}
$$

where $X$ is the molar ratio of $\mathrm{CO}_{2}$ or $\mathrm{N}_{2}$ in the adsorbed phase and $Y$ is the molar ratio in the gas phase.

Thermal response measurements were performed at 1 bar and $298 \mathrm{~K}$ on an optical calorimeter (InfraSORP). ${ }^{44}$ For the $\mathrm{CO}_{2}$ adsorption/desorption measurements, $\sim 30 \mathrm{mg}$ of the C-HAT$\mathrm{CN}-X$ materials were placed in the sample holder, and purged under $\mathrm{N}_{2}$ flow of $72 \mathrm{sccm}$ until a constant sample temperature was observed. Then, the sample was exposed to a $\mathrm{CO}_{2}$ flow of 72 sccm for 100 seconds. Finally, $\mathrm{N}_{2}$ flow was directed to the sample cell again for $200 \mathrm{~s}$ causing a decrease in temperature due to desorption of the test gas. The peak areas $(A)$ of the thermal response curves have been integrated using 
OriginPro2015 software. The peak area was divided by the sample mass used for the measurements and is also normalized to the total pore volume.

The $\mathrm{CO}_{2}$ adsorption cycling experiments were performed using similar gas flow and time-programmed conditions.

All X-ray powder diffraction (XRPD) patterns were collected on a Bruker D8 Advanced diffractometer equipped with a scintillation counter detector using $\mathrm{Cu} K \alpha$ radiation $(\lambda=0.1518 \mathrm{~nm})$ in the $2 \theta$ range from $5^{\circ}$ to $70^{\circ}$ with a step size of $0.03^{\circ}$ and counting time $1 \mathrm{~s}$ per step. Possible impurity phases were checked by comparing XRPD patterns with those in the PDF4 database (powder diffraction file, ICDD, release 2016).

$\mathrm{C} / \mathrm{H} / \mathrm{N}$ Elemental analysis (EA) was accomplished as combustion analysis using a Vario Micro device. The oxygen content of the samples was calculated from the residual amount of the EA which has not been detected as $\mathrm{C}, \mathrm{H}$, or $\mathrm{N}$.

Fourier-transform infrared (FTIR) spectra were recorded on a Varian 1000 spectrometer with an attenuated total reflectance setup.

Thermogravimetric analysis (TGA) measurements were performed using a thermo microbalance TG 209 F1 Libra (Netzsch, Selb, Germany). A platinum crucible was used for the measurement of $10 \pm 1 \mathrm{mg}$ of samples in a $\mathrm{N}_{2}$ flow of 10 $\mathrm{mL} \min ^{-1}$ and a purge flow of $10 \mathrm{~mL} \mathrm{~min}^{-1}$. Additional 5 $\mathrm{mL} \min ^{-1} \mathrm{O}_{2}$ flow has been used for the measurements in synthetic air. The samples were heated to $1000{ }^{\circ} \mathrm{C}$ with a heating rate of $5{ }^{\circ} \mathrm{C} \mathrm{min}^{-1}$. The data was recorded and analysed by the Proteus (6.0.0) and Quadstar (7.03) software package.

Solid-state nuclear magnetic resonance (ssNMR) spectra were recorded with a Bruker Avance $400 \mathrm{MHz}$ spectrometer operating at $100.56 \mathrm{MHz}$ for ${ }^{13} \mathrm{C} .{ }^{13} \mathrm{C}\left\{{ }^{1} \mathrm{H}\right\}$ magic angle spinning (MAS) ssNMR experiments were carried out at a spinning rate of $10 \mathrm{kHz}$ using $4 \mathrm{~mm}$ MAS HX double resonance probe. The ${ }^{13} \mathrm{C}$ $\pi / 2$ pulse length were $3.0 \mu$ s. Two pulse phase modulation (TPPM) heteronuclear dipolar decoupling was used during acquisition and a recycle delay of $20 \mathrm{~s}$ was implemented. All ${ }^{13} \mathrm{C}$ $\left\{{ }^{1} \mathrm{H}\right\}$ spectra are referenced to external TMS at 0 ppm using solid adamantine as a secondary reference.

Details of the electron microscopy characterization of the samples and computational details are given in the ESI. $\dagger$

\section{Results and discussion}

\section{Structure of the HAT-CN-derived carbon materials}

Thermal condensation of HAT-CN by elimination of the nitrile groups in the temperature range of $500-700{ }^{\circ} \mathrm{C}$ leads to the formation of nitrogen-rich carbon materials with a $\mathrm{C}_{2} \mathrm{~N}$-like stoichiometry (Fig. S1†). C-HAT-CN-500 and C-HAT-CN-525 show nitrogen contents of 31-34 at\%, as determined by elemental analysis (EA) (Table 1). The significant amount of hydrogen and oxygen detected in these measurements likely arises from water adsorbed on the samples. The $\mathrm{C} / \mathrm{N}$ atomic ratio of C-HAT-CN-500 (1.55) is only marginally higher than in HAT-CN (1.53). This indicates that no major condensation of the nitrile groups occurs at this temperature. After condensation at $525{ }^{\circ} \mathrm{C}$ and $550{ }^{\circ} \mathrm{C}$, the $\mathrm{C} / \mathrm{N}$ ratios increase to 1.60 and 1.67, respectively. Finally, at $700{ }^{\circ} \mathrm{C}$, the ratio reached 1.96 and a nearly perfect $\mathrm{C}_{2} \mathrm{~N}$-type material is obtained. According to our previous findings, condensation of the HAT-CN precursor molecule with a composition of $\mathrm{C}_{18} \mathrm{~N}_{12}$ releases cyanogen $\left(\mathrm{C}_{2} \mathrm{~N}_{2}\right)$ as the condensation byproduct. It can thus be assumed that the condensation proceeds according to the general equation $\mathrm{C}_{18} \mathrm{~N}_{12(\mathrm{~s})} \rightarrow \mathrm{C}_{12} \mathrm{~N}_{6(\mathrm{~s})}+3 \mathrm{C}_{2} \mathrm{~N}_{2(\mathrm{~g})}$. In agreement with thermal analysis of HAT-CN under inert atmosphere (Fig. S2 $\dagger$ ), there seems to be a sharp onset point of this condensation reaction located at $500{ }^{\circ} \mathrm{C}$ or slightly below. The yield of nitrogen-rich carbon material after condensation at $500{ }^{\circ} \mathrm{C}$ is $70 \%$ and drops significantly to $51 \%$ after thermal treatment at $525{ }^{\circ} \mathrm{C}$ and to $33 \%$ after reaction at $700{ }^{\circ} \mathrm{C}$, which is in good accordance with the TGA experiment. These elemental compositions and yields do not only reveal that HAT-CN is a very well-suited precursor molecule for the synthesis of $\mathrm{C}_{2} \mathrm{~N}$ materials, but also that the degree of condensation (and with it the chemical and textural properties of the resulting materials) is precisely adjustable via the condensation temperature because the nitrogen content decreases at higher condensation degree due to the release of cyanogen.

FTIR (Fig. 1a) and XRPD (Fig. 1b) measurements further indicate a distinct structural change between $500{ }^{\circ} \mathrm{C}$ and $550{ }^{\circ} \mathrm{C}$, resulting from condensation of the HAT-CN monomer. The XRD pattern of C-HAT-CN-500 is still in nearly perfect accordance to the pattern of the untreated HAT-CN. The crystal structure is still intact after heating to $525{ }^{\circ} \mathrm{C}$, but there is already a notable contribution of defects in the HAT structure, as can be seen by the obvious distortion of the baseline underneath the characteristic peaks in the $2 \theta$ range from 10 to $30^{\circ}$. The contribution of amorphous scattering intensity at very low $2 \theta$ values can be indicative for the development of narrow pores. This is not observed for the HAT-CN and increases in intensity from C-HAT-CN-500 to C-HAT-CN-525. In accordance with our recent study, C-HAT-CN-550 and C-HAT-CN-700 have an amorphous structure as it is typical for high surface-area carbons. The (002) peak (representing graphitic stacking in the structure) has low intensity and can be found in the $2 \theta$ range from 25 to $30^{\circ}$. Its maximum shifts to a slightly lower angle with increasing condensation temperature.

Table 1 Elemental analysis data of HAT-CN and the condensed materials as well as corresponding condensation yields

\begin{tabular}{|c|c|c|c|c|c|}
\hline Material & $\mathrm{C}_{\mathrm{EA}} / \mathrm{at} \%(\mathrm{wt} \%)$ & $\mathrm{N}_{\mathrm{EA}} / \mathrm{at} \%(\mathrm{wt} \%)$ & $\mathrm{H}_{\mathrm{EA}} / \mathrm{at} \%(\mathrm{wt} \%)$ & $\mathrm{O}_{\mathrm{EA}} / \mathrm{at} \%(\mathrm{wt} \%)$ & Yield/\% \\
\hline HAT-CN & $53.9(55.8)$ & $35.3(42.6)$ & $10.3(0.9)$ & $0.3(0.6)$ & - \\
\hline C-HAT-CN-500 & $52.5(54.1)$ & $33.9(40.8)$ & $10.6(0.9)$ & $3.0(4.2)$ & 70 \\
\hline C-HAT-CN-550 & $43.7(48.4)$ & $26.2(33.7)$ & $19.3(1.8)$ & $10.9(16.1)$ & 50 \\
\hline C-HAT-CN-700 & $42.5(50.5)$ & $21.7(30.1)$ & $25.0(2.5)$ & $10.7(16.9)$ & 33 \\
\hline
\end{tabular}


a)

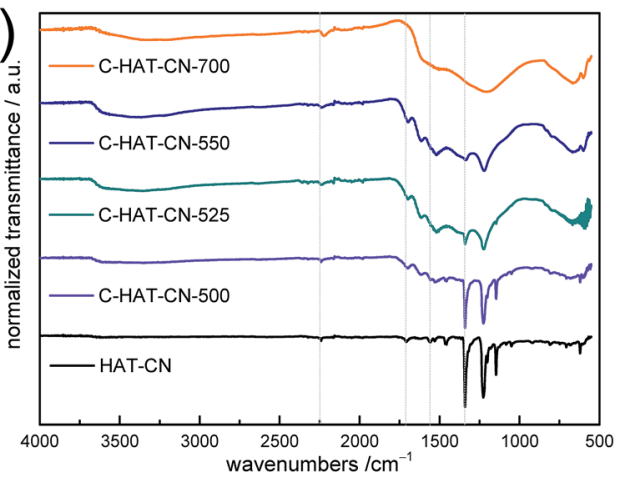

b)

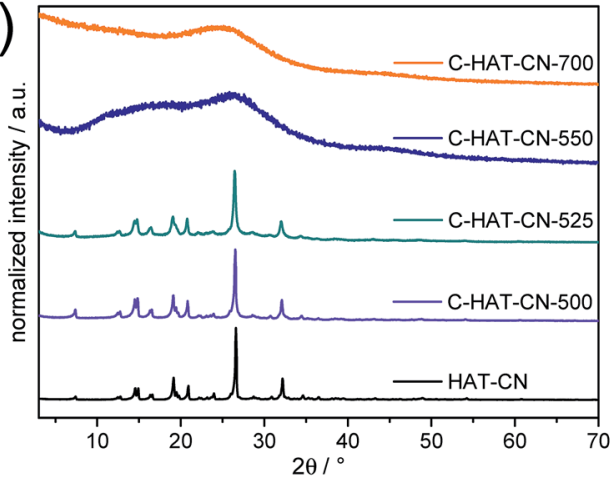

c)

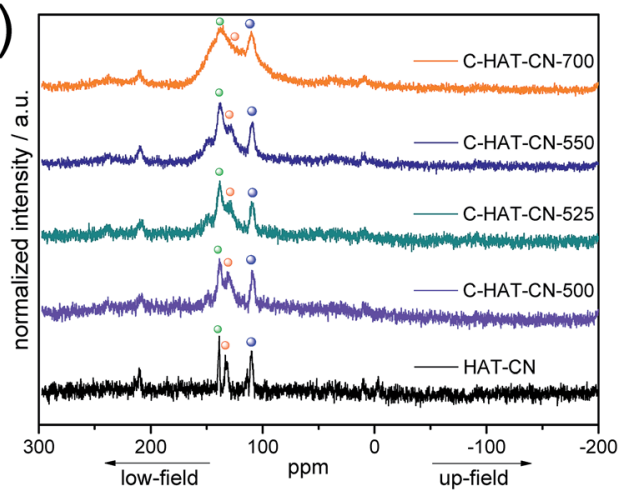

Fig. 1 FTIR spectra (a), XRPD patterns (b), and ${ }^{13} \mathrm{C}$ CP-MAS ssNMR spectra (c) of HAT-CN, C-HAT-CN-500, C-HAT-CN-525, C-HAT$\mathrm{CN}-550$, and $\mathrm{C}-\mathrm{HAT}-\mathrm{CN}-700$. In (c), the green circle is marking aromatic carbon in the inner benzene ring, the orange circle marks the pyrazinic carbon, and blue circle corresponds to the nitrile carbon.

FTIR spectra of the HAT-CN show sharp and narrow peaks, which disappear or get broader with increasing condensation temperature. The intense peak at $1339 \mathrm{~cm}^{-1}$ originates from $\mathrm{C}-\mathrm{N}$ stretching vibrations. The $\mathrm{C}=\mathrm{N}$ and $\mathrm{C}=\mathrm{C}$ vibrations in the aromatic ring system appear at $1708 \mathrm{~cm}^{-1}$ and $1560 \mathrm{~cm}^{-1}$, respectively. The peak at $2240 \mathrm{~cm}^{-1}$ is attributed to the nitrile $\mathrm{C} \equiv \mathrm{N}$ groups. This peak does not disappear as the carbonization temperature increases. This might be related to the nitrile groups located on the edges of the carbon network. In accordance with EA and XRPD measurements, the spectra show that there is a continuous increase of the condensation degree with increasing synthesis temperature.

The chemical environment of carbon atoms in HAT-CN and HAT-CN-derived carbon materials is investigated by ${ }^{13} \mathrm{C}\left\{{ }^{1} \mathrm{H}\right\}$ magic angle spinning (MAS) solid-state (ss) NMR experiments
(Fig. 1c). Three characteristic peaks for HAT-CN are present. The peak at $\sim 132 \mathrm{ppm}$ (marked with an orange circle) corresponds to aromatic carbon atoms in the inner benzene ring of the HAT$\mathrm{CN}$ molecule. The peak at $\sim 139 \mathrm{ppm}$ (green circle) corresponds to the pyrazinic carbon, and the one at $\sim 110 \mathrm{ppm}$ (blue circle) to the nitrile carbon. ${ }^{45}$ As expected for a well crystallized organic molecule, the peaks for HAT-CN are sharp and well separated. The condensation of the organic molecule towards a porous amorphous network clearly leads to broadening of the peaks which gets more pronounced at increasing temperature. The peak of the nitrile carbons remains for the C-HAT-CN-700, but weakens. This is due to the surface terminations at grain boundaries of the porous network particles, as it was already shown in the FTIR spectra.

Besides the atomic construction, the porosity of the HATderived carbon materials is also controllable by the synthesis temperature. In our recent study on HAT-CN-derived $\mathrm{C}_{2} \mathrm{~N}$ materials, it has been shown that (despite the absence of any additional porogen) condensation at $550{ }^{\circ} \mathrm{C}$ or above leads to the formation of structural microporosity. ${ }^{41}$ The Ar physisorption $\left(-186^{\circ} \mathrm{C}\right)$ isotherm (Fig. 2a) shows that the C-HAT$\mathrm{CN}-700$ material with near-ideal $\mathrm{C}_{2} \mathrm{~N}$-stoichiometry has indeed a high specific BET surface area and a significant total pore volume of $785 \mathrm{~m}^{2} \mathrm{~g}^{-1}$ and $0.31 \mathrm{~cm}^{3} \mathrm{~g}^{-1}$, respectively. Starting from the HAT-CN with no notable surface area, there is a stepwise increase of the porosity detected with $\mathrm{Ar}$ at $-186{ }^{\circ} \mathrm{C}$ with increasing condensation temperature. Whereas the samples CHAT-CN-500 and C-HAT-CN-525 still do not show any notable uptake of $\mathrm{Ar}$, condensation at $550{ }^{\circ} \mathrm{C}$ forms a material with
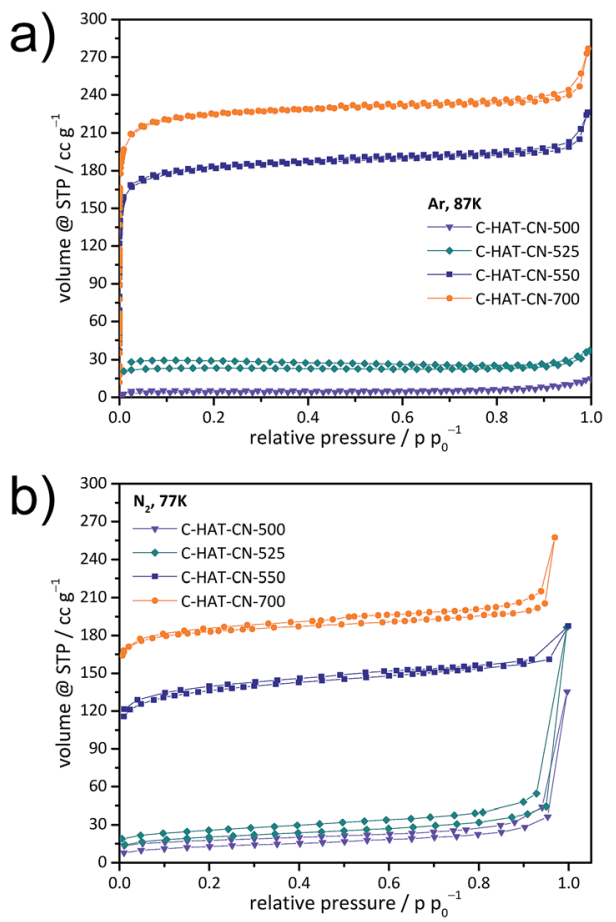

Fig. 2 Ar physisorption isotherms $\left(-186^{\circ} \mathrm{C}\right)$ (a) and $\mathrm{N}_{2}$ physisorption isotherms $\left(-196^{\circ} \mathrm{C}\right)$ (b) of C-HAT-CN-500, C-HAT-CN-525, C-HAT$\mathrm{CN}-550$, and C-HAT-CN-700. 
a BET surface area of $627 \mathrm{~m}^{2} \mathrm{~g}^{-1}$ and a total pore volume of 0.24 $\mathrm{cm}^{3} \mathrm{~g}^{-1}$. The lager pore volume of C-HAT-CN-700 is the consequence of further increasing pore size with increasing degree of condensation (Fig. S3 $\uparrow$ ). The micropore volume detected for CHAT-CN-700 with Ar physisorption at $-186{ }^{\circ} \mathrm{C}\left(0.30 \mathrm{~cm}^{3} \mathrm{~g}^{-1}\right)$ is comparable to the one detected with $\mathrm{N}_{2}$ physisorption at $-196{ }^{\circ} \mathrm{C}\left(0.27 \mathrm{~cm}^{3} \mathrm{~g}^{-1}\right.$, Fig. $\left.2 \mathrm{~b}\right)$. Notably, the difference for CHAT-CN-550 is much larger. In this material, Ar physisorption analysis detects a micropore volume of $0.24 \mathrm{~cm}^{3} \mathrm{~g}^{-1}$, whereas nitrogen physisorption analysis only results in a micropore volume of $0.20 \mathrm{~cm}^{3} \mathrm{~g}^{-1}$. This indicates accessibility limitations for the slightly larger $\mathrm{N}_{2}$ molecules with higher quadrupole moment at lower measurement temperature into the very small micropores of C-HAT-CN-550. In other words, these materials are possible molecular sieves, not only for $\mathrm{CO}_{2} / \mathrm{N}_{2}$ adsorption, but also for $\mathrm{Ar} / \mathrm{N}_{2}$ adsorption. The preferred adsorption is based on a kinetic size exclusion on the expense of the (even stronger adsorbing) nitrogen molecules, that is, a (kinetic) molecular sieving effect. The uptakes of argon and nitrogen at relative pressures close to 1 bar are due to adsorption in the larger pores, which is in line with the TEM investigations as discussed below.

In order to utilize these materials for selective $\mathrm{CO}_{2} / \mathrm{N}_{2}$ capture based on molecular sieving, a pore size close to the dimensions of the $\mathrm{CO}_{2}$ molecules, but smaller than for $\mathrm{N}_{2}$, is required. On the other hand, the internal surface of the materials should be highly polarizing in order to have a high adsorption affinity towards $\mathrm{CO}_{2} \cdot \mathrm{H}_{2} \mathrm{O}$ vapor (a molecule with even higher adsorption enthalpy than $\mathrm{CO}_{2}$ and thus a wellsuited probe for the presence of polar adsorption sites) physisorption isotherms of the samples show an extremely polar character of the pore walls in all HAT-CN-derived materials, as indicated by the significant water uptake at low relative pressures (Fig. S4 $\dagger$ ). The adsorbed volumes follow the available pore volumes detected with Ar physisorption. It should be noted that the strong interaction with $\mathrm{H}_{2} \mathrm{O}$ will of course remain a problem for $\mathrm{CO}_{2}$ separation with these materials under practical conditions.

High-resolution transmission electron microscopy (HRTEM) as well as annular dark-field scanning transmission electron microscopy (ADF-STEM) images of the condensed HAT-CN materials (Fig. 3 and S5 $\dagger$ ) show the presence of an amorphous, covalent, carbonaceous microstructure without distinct stacking of layers in the C-HAT-CN-550 and C-HAT-CN-700, which is typical for highly microporous carbon materials and in line with our previous findings. ${ }^{41}$ This highly disordered structure likely results from the rapid condensation due to elimination of the nitrile groups of HAT-CN. C-HAT-CN-500 and C-HAT-CN-525 show an amorphous carbon microstructure in the TEM images. In combination with the XRPD results (Fig. 1b), this indicates that the condensed HAT-CN materials consist of crystalline and amorphous constituents. The C-HAT$\mathrm{CN}$ materials seem to have a core-shell-like structure with a distinct difference between the constructions of the inner and outer areas of the individual disk-shaped particles (Fig. S5†). While the inner areas consist of a 3-dimensional network of
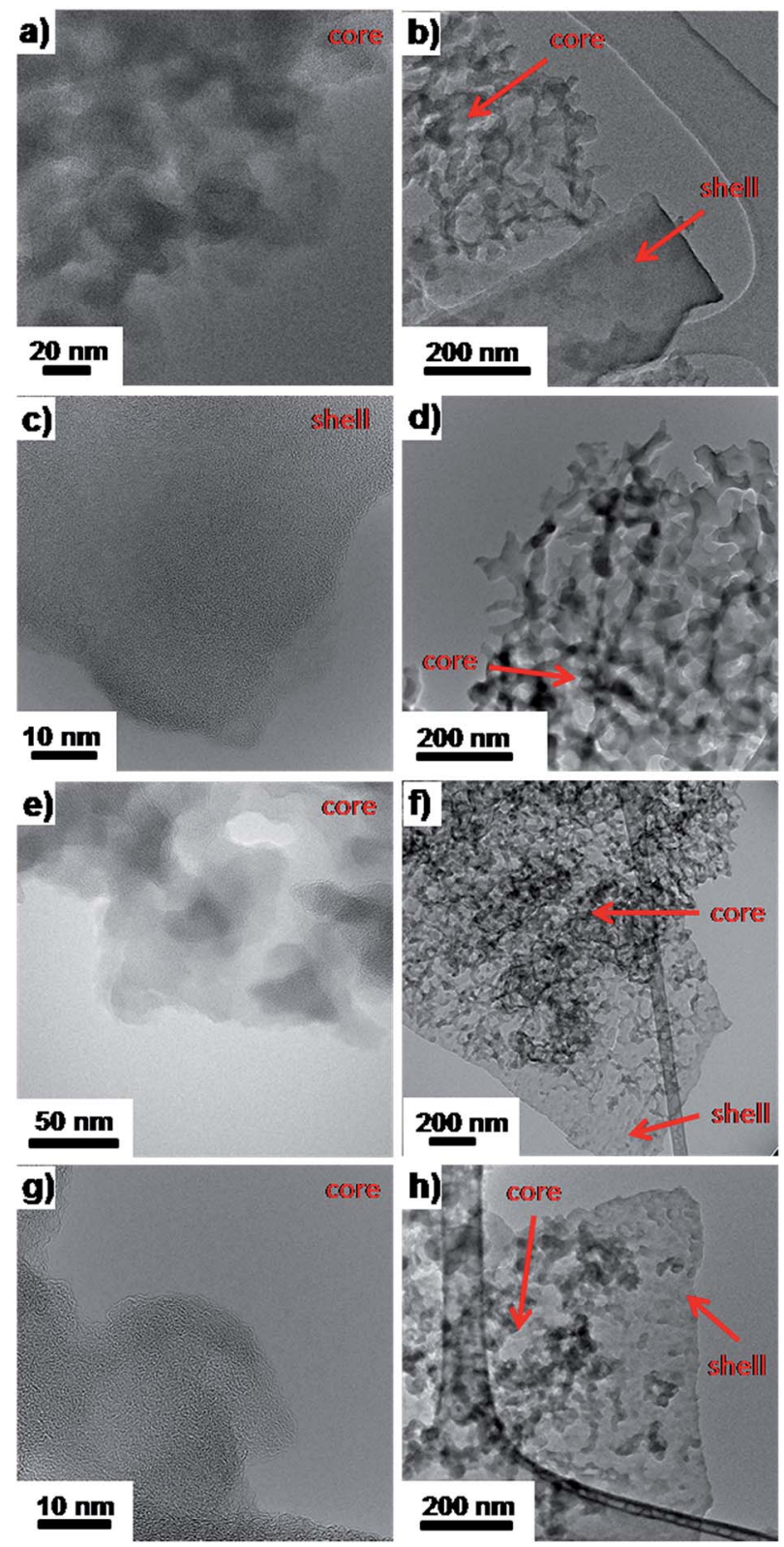

Fig. 3 HRTEM images of C-HAT-CN-700 (a) and (b), C-HAT-CN-550 (c) and (d), C-HAT-CN-525 (e) and (f), and C-HAT-CN-500 (g) and (h). Constituents of core and shell areas are labelled in the images.

agglomerated small grains with larger pores in between, the double-walled shell has a rather dense appearance.

\section{$\mathrm{CO}_{2} / \mathrm{N}_{2}$ molecular sieving with HAT-CN-derived carbon materials}

The narrow pore size of the HAT-CN-derived carbons can be rather precisely adjusted by the synthesis temperature, and the materials generally have a very polar surface resulting from their high nitrogen content. On the one site, these pyrazinic nitrogen sites have basic and electron-donating properties which are particularly strong in the $\mathrm{C}_{2} \mathrm{~N}$ structure and able to strongly bind to the electrophilic carbon atom in $\mathrm{CO}_{2}$. A 
synergistic effect can be achieved by the similar presence of electron deficient carbon atoms in the $\mathrm{C}_{2} \mathrm{~N}$ which can strongly rebind to the nucleophilic oxygen atoms in $\mathrm{CO}_{2}$. These properties render the materials attractive candidates for selective adsorption of $\mathrm{CO}_{2}$ in the presence of $\mathrm{N}_{2}$.

$\mathrm{CO}_{2}$ and $\mathrm{N}_{2}$ physisorption isotherms of the HAT-CN-derived carbon materials at $0{ }^{\circ} \mathrm{C}$ and $25{ }^{\circ} \mathrm{C}$ show a maximum IAST $\mathrm{CO}_{2} / \mathrm{N}_{2}$ selectivity of 121 for the C-HAT-CN-525 (Table 2 and Fig. 4). In this material, the pores are already large enough to adsorb a significant amount of $\mathrm{CO}_{2}$, but are not yet too large to take up high volumes of $\mathrm{N}_{2}$. At higher synthesis temperatures, $\mathrm{CO}_{2}$ uptakes increase further as a result of the increasing pore volume, but the $\mathrm{CO}_{2} / \mathrm{N}_{2}$ selectivity decreases. At both temperatures, the selectivity of C-HAT-CN-550 with smaller pores is still higher than for C-HAT-CN-700. This confirms that the use of materials with a high $\mathrm{N}_{2}$ surface area is not suitable for selective $\mathrm{CO}_{2}$ capture, as long as high selectivity is required because of the increasing contribution of less discriminative van der Waals interactions. ${ }^{8}$ In accordance to the nanostructure and nitrogen content, C-HAT-CN-525 shows a significantly higher isosteric heat $\left(Q_{\mathrm{st}}\right)$ of $\mathrm{CO}_{2}$ adsorption (Table 2 and Fig. S6†) of $\sim 52 \mathrm{~kJ} \mathrm{~mol}^{-1}$ as compared to C-HAT-CN-550 $\left(\sim 36 \mathrm{~kJ} \mathrm{~mol}^{-1}\right)$ and C-HAT-CN-700 $\left(\sim 42 \mathrm{~kJ} \mathrm{~mol}^{-1}\right)$. It should be mentioned that these numbers may have a relatively high experimental error but such a high $Q_{\text {st }}$ is the result of the high nitrogen content, as well as the pore size, which is perfectly tuned for the molecular encapsulation of $\mathrm{CO}_{2}$. Typically, isosteric heats of adsorption, as well as IAST $\mathrm{CO}_{2} / \mathrm{N}_{2}$ selectivity in this range are only achievable with metal-containing materials including coulomb charges. ${ }^{8,24,33}$ In this way, C-HAT-CN-525 indeed combines the necessary requirements for highly selective $\mathrm{CO}_{2}$ capture, which are molecular sieving and an atomic construction tuned for strong $\mathrm{CO}_{2}$ binding (i.e., separation of the electron density between carbon and nitrogen atoms) without the need for any metal.

Thermal response measurements of $\mathrm{CO}_{2}$ adsorption with the InfraSORP technology ${ }^{44}$ (Fig. 5a) provide further information about $\mathrm{CO}_{2}$ adsorption capacities and kinetics of the HAT-CNderived materials. In line with the volumetric measurements, the highest temperature peak areas are present for C-HAT-CN700 and C-HAT-CN-550 due to their large micropores, and thus highest $\mathrm{CO}_{2}$ uptake at 1 bar. Regarding their very low $\mathrm{Ar}$ and $\mathrm{N}_{2}$ accessible microporosity, the significant temperature signals of C-HAT-CN-525 and C-HAT-CN-500 are remarkable. According to their higher $Q_{\mathrm{st}}$ values their normalized peak areas (divided by mass and the total pore volumes determined with $\mathrm{Ar}$ physisorption) are significantly higher as compared to the
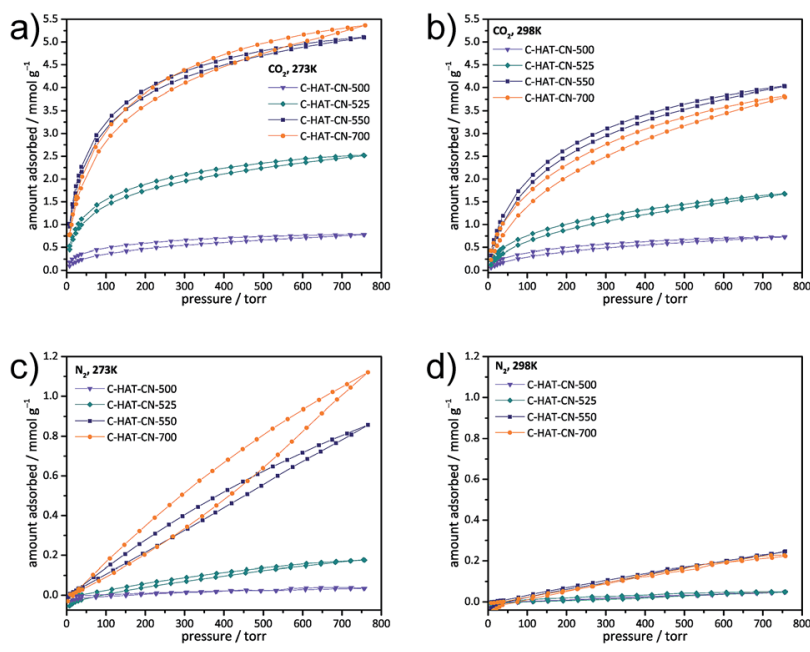

Fig. $4 \mathrm{CO}_{2}$ (a) and (b), as well as $\mathrm{N}_{2}$ (c) and (d) physisorption isotherms of C-HAT-CN-500, C-HAT-CN-525, C-HAT-CN-550, and C-HAT$\mathrm{CN}-700$ measured at $0{ }^{\circ} \mathrm{C}$ (a) and (c) and at $25^{\circ} \mathrm{C}$ (b) and (d).

materials obtained by HAT-CN condensation at higher temperatures (Fig. 5b). The mass-related peak areas for adsorption and desorption are nearly similar for one and the same material, indicating no occurrence of irreversible binding of $\mathrm{CO}_{2}$. Compared to a microporous carbide-derived carbon material (TiC-CDC, synthesized at $800{ }^{\circ} \mathrm{C}$ ) ${ }^{44}$ the presence of specific $\mathrm{CO}_{2}$ binding sites is further indicated by the minor asymmetry in the adsorption and desorption temperature signals in the cases of the C-HAT-CN materials (Fig. 5c and 5d). The $\mathrm{CO}_{2}$ desorption process by flushing with $\mathrm{N}_{2}$ causes a slightly lower peak temperature decrease than the adsorption of $\mathrm{CO}_{2}$. This is typical for materials with narrow pores and abundant nitrogen sites, and thus not observable for the heteroatom-free TiC-CDC with slightly larger micropores. The latter is showing rather symmetrical and "sharp" temperature signals in $\mathrm{CO}_{2}$ adsorption.

Despite the high $\mathrm{CO}_{2}$ adsorption enthalpy of C-HAT-CN-525, the binding is fully reversible for 80 cycles by simple flushing with $\mathrm{N}_{2}$ (Fig. S7†). This means, that this molecular sieving concept is applicable to simple pressure swing adsorption without loss of $\mathrm{CO}_{2}$ separation efficiency over time.

\section{Calculation of the $\mathrm{CO}_{2}$ adsorption state on $\mathrm{C}_{2} \mathrm{~N}$}

An atomistic model of the adsorption state of $\mathrm{CO}_{2}$ on an idealized C-HAT-CN material with perfect $\mathrm{C}_{2} \mathrm{~N}$-type

Table 2 Argon physisorption $\left(-186^{\circ} \mathrm{C}\right.$ ) data summary, selectivity of $\mathrm{CO}_{2}$ over $\mathrm{N}_{2}\left(\right.$ at $0{ }^{\circ} \mathrm{C}$ and $25^{\circ} \mathrm{C}$ ), and isosteric heat of adsorption $\left(Q_{\mathrm{st}}\right)$ of $\mathrm{CO}$, of C-HAT-CN-500, C-HAT-CN-525, C-HAT-CN-550, and C-HAT-CN-700

\begin{tabular}{|c|c|c|c|c|c|c|}
\hline \multirow[b]{2}{*}{ Material } & \multirow[b]{2}{*}{$\mathrm{SSA}_{\mathrm{BET}} / \mathrm{m}^{2} \mathrm{~g}^{-1}$} & \multirow[b]{2}{*}{$\mathrm{SSA}_{\mathrm{DFT}} / \mathrm{m}^{2} \mathrm{~g}^{-1}$} & \multirow[b]{2}{*}{$V_{\text {Total }} / \mathrm{cm}^{3} \mathrm{~g}^{-1}$} & \multicolumn{2}{|c|}{ Selectivity $/ \mathrm{CO}_{2} / \mathrm{N}_{2}$} & \multirow[b]{2}{*}{$Q_{\mathrm{st}} / \mathrm{kJ} \mathrm{mol}^{-1}$} \\
\hline & & & & $273 \mathrm{~K}$ & $298 \mathrm{~K}$ & \\
\hline C-HAT-CN-500 & 13 & 13 & 0.01 & - & - & - \\
\hline C-HAT-CN-525 & 82 & 172 & 0.03 & 72 & 121 & 52 \\
\hline C-HAT-CN-550 & 627 & 1013 & 0.24 & 34 & 65 & 36 \\
\hline C-HAT-CN-700 & 785 & 1182 & 0.31 & 23 & 53 & 42 \\
\hline
\end{tabular}


a)
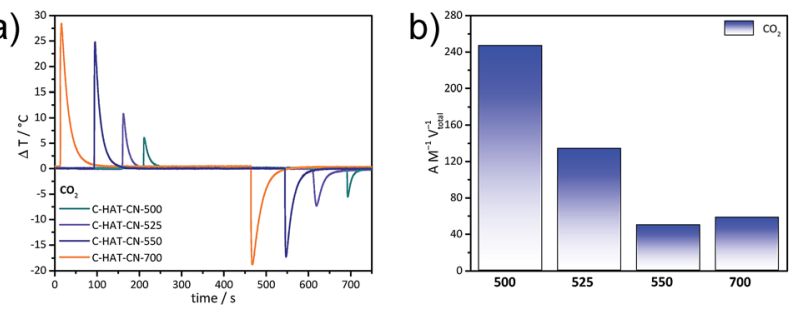

c)
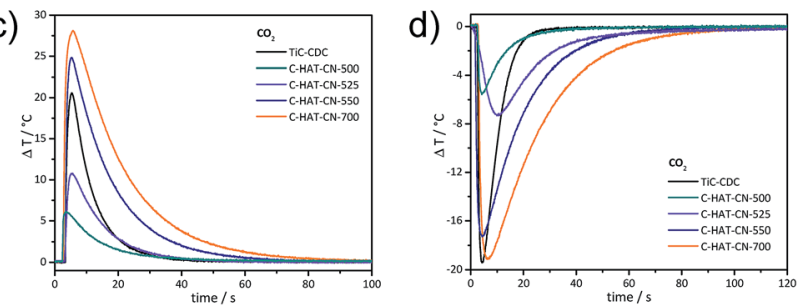

Fig. $5 \mathrm{CO}_{2}$ thermal response adsorption and desorption measurements at 1 bar and $25^{\circ} \mathrm{C}$ (a), integrated adsorption temperature peak area normalized by mass and total pore volume (b) of C-HAT-CN-500, C-HAT-CN-525, C-HAT-CN-550, and C-HAT-CN-700, as well as their adsorption (c) and desorption (d) thermal response curves at higher magnifications together with a microporous non-nitrogendoped carbon material (TiC-CDC) for comparison.

stoichiometry and AAA-type layer stacking (Fig. 6a) has been obtained by dynamical simulated annealing ${ }^{46,47}$ using the second-generation Car-Parrinello molecular dynamics approach of Kühne et al. (computational details are described in the $\mathrm{ESI}+)^{48,49}$ We find that the $\mathrm{CO}_{2}$ molecules are oriented orthogonal to the $\mathrm{C}_{2} \mathrm{~N}$-planes occupying every second vacancy in a checkerboard-like fashion. This energy minimization arises from collective stabilization effects from the nitrogen atoms in the $\mathrm{C}_{2} \mathrm{~N}$ layers surrounding the carbon atom in the $\mathrm{CO}_{2}$ molecule and due to the electron acceptor properties of the carbon atoms from $\mathrm{C}_{2} \mathrm{~N}$ in close proximity to the oxygen atoms in $\mathrm{CO}_{2}$. In simple words, all atoms of the gas molecule are surrounded in their electronically favourable environment. In the present supercell, which contains of 4 layers with 4 holes each, the insertion of $8 \mathrm{CO}_{2}$ molecules entails an adsorption energy of
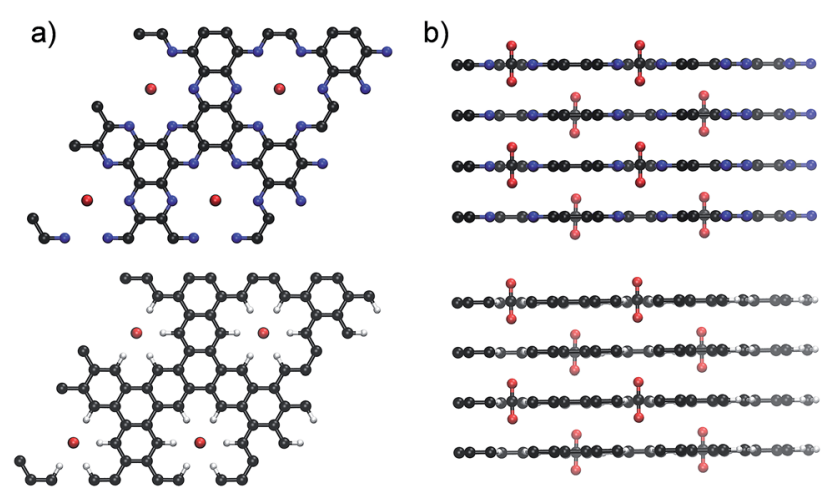

Fig. 6 Lowest energy structure of $\mathrm{C}_{2} \mathrm{~N}$ with maximum amount of $\mathrm{CO}_{2}$ molecules adsorbed (top). For comparison the considered control system of $\mathrm{C}_{3} \mathrm{H}$ stoichiometry is also shown (bottom). Left: top views (a); right: side views (b).
$-231.5 \mathrm{~kJ} \mathrm{~mol}^{-1}$ that equals to $-29 \mathrm{~kJ} \mathrm{~mol}^{-1}$ per molecule. This $Q_{\text {st }}$ value is slightly lower as compared to the experimental value determined for the C-HAT-CN-700 material. In accordance with our gas physisorption data, this indicates that the pore size in the experimental sample is lower than in the idealized $\mathrm{C}_{2} \mathrm{~N}$ material used for the theoretical calculations with pores which would result from perfect AAA stacking. Another possible reason for the higher experimental $Q_{\text {st }}$ value could be the overlapping of the adsorption potentials from two pore walls in narrow cavities which is not taken into consideration by the theoretical calculations. In the corresponding nitrogen-free control system with $\mathrm{C}_{3} \mathrm{H}$ stoichiometry, all nitrogen atoms have been substituted by $\mathrm{C}-\mathrm{H}$ groups. In this case, the adsorption energy is strictly positive being as high as $+206 \mathrm{~kJ} \mathrm{~mol}^{-1}$ (Fig. 6b). No energetically favourable coordination of $\mathrm{CO}_{2}$ takes place in this environment.

\section{Conclusions}

We have shown that the thermal condensation of HAT-CN is a process that produces extremely nitrogen-rich carbon materials under precise control over the molecular composition and nanostructure/porosity. At a condensation temperature of $525{ }^{\circ} \mathrm{C}$, pores start forming with a size that allows for $\mathrm{CO}_{2} / \mathrm{N}_{2}$ molecular sieving. To the best of our knowledge, this is the first time that a metal-free and non-organic material with an isosteric heat of $\mathrm{CO}_{2}$ adsorption of up to $52 \mathrm{~kJ} \mathrm{~mol}^{-1}$ and a $\mathrm{CO}_{2} / \mathrm{N}_{2}$ selectivity of more than 100 has been prepared.

These properties are mainly related to the combination of strong binding of $\mathrm{CO}_{2}$ (provided by negatively polarized nitrogen atoms and positively polarized carbon atoms) as a result of the combination of the atomic construction with the narrow pore size of the C-HAT-CN materials. A defined pore size alone for $\mathrm{CO}_{2}$ adsorption is useless as the capture will become too slow and a designed chemical construction combined with too large pores is also not beneficial, as then the selectivity is limited by non-discriminative van der Waals interactions.

As it can be assumed that only a small part of the bulk volume present in C-HAT-CN-525 is really used for $\mathrm{CO}_{2}$ binding, the logical next step would be the synthesis of a hierarchical $\mathrm{C}_{2} \mathrm{~N}$-type material in order to shorted mass transport pathways and thus to enhance the accessibility of the internal pore volume. This approach is currently applied in zeolite research $^{50,51}$ and will also help in case of such "organic zeolites". On the other hand, the insertion of extra-framework cations in these materials may be an approach to further increase the $\mathrm{CO}_{2}$ adsorption enthalpy. The main focus of this work was to illuminate the origin of the strong interaction between $\mathrm{CO}_{2}$ and nitrogen-rich carbon materials prepared by molecular design. After the general possibility of $\mathrm{CO}_{2}$ molecular sieving with metal-free materials has been shown in this work, the applicability of such materials under real-world conditions, as well as the kinetics of $\mathrm{CO}_{2}$ adsorption, has to be further investigated with mixed-gas breakthrough experiments under wet conditions. 
Finally, this synthetic concept towards such zeolite-like carbon materials is potentially also applicable for the separation of other relevant gas mixtures.

\section{Conflicts of interest}

There are no conflicts to declare.

\section{Acknowledgements}

R. W. and M. O. thank the German Chemical Industry Fund (Fonds der Chemischen Industrie, FCI) for financial support with a Liebig Fellowship. J.H, S.S. and T.D.K acknowledges funding from the European Research Council (ERC) under the European Union's Horizon 2020 research and innovation programme (grant agreement No 716142). The authors would like to thank the Paderborn Center for Parallel Computing $\left(\mathrm{PC}^{2}\right)$ for the generous allocation of computing time on the FPGA-based supercomputer "Noctua". The authors would like to thank Ms. Bolortuya Badamdorj for help with collecting TEM images. Open Access funding provided by the Max Planck Society.

\section{References}

1 F. A. Rahman, M. M. A. Aziz, R. Saidur, W. A. W. A. Bakar, M. R. Hainin, R. Putrajaya and N. A. Hassan, Renewable Sustainable Energy Rev., 2017, 71, 112-126.

2 E. S. Sanz-Perez, C. R. Murdock, S. A. Didas and C. W. Jones, Chem. Rev., 2016, 116, 11840-11876.

3 D. M. D'Alessandro, B. Smit and J. R. Long, Angew. Chem., Int. Ed., 2010, 49, 6058-6082.

4 R. S. Hazeldine, Science, 2009, 325, 1647-1652.

5 B. Dutcher, M. Fan and A. G. Russell, ACS Appl. Mater. Interfaces, 2015, 7, 2137-2148.

6 C. Gouedard, D. Picq, F. Launay and P. L. Carrette, Int. J. Greenhouse Gas Control, 2012, 10, 244-270.

7 F. Inagaki, C. Matsumoto, T. Iwata and C. Mukai, J. Am. Chem. Soc., 2017, 139, 4639-4642.

8 M. Oschatz and M. Antonietti, Energy Environ. Sci., 2018, 11, 57-70.

9 Y. S. Bae and R. Q. Snurr, Angew. Chem., Int. Ed., 2011, 50, 11586-11596.

10 X. Lu, D. Jin, S. Wei, Z. Wang, C. An and W. Guo, J. Mater. Chem. A, 2015, 3, 12118-12132.

11 O. Cheung and N. Hedin, RSC Adv., 2014, 4, 14480-14494.

12 M. Abu Ghalia and Y. Dahman, Energy Technol., 2017, 5, 356372.

13 F. Akhtar, Q. Liu, N. Hedin and L. Bergström, Energy Environ. Sci., 2012, 5, 7664-7673.

14 R. Banerjee, H. Furukawa, D. Britt, C. Knobler, M. O'Keeffe and O. M. Yaghi, J. Am. Chem. Soc., 2009, 131, 3875-3877.

15 F. Gao, Y. Li, Z. Bian, J. Hu and H. Liu, J. Mater. Chem. A, 2015, 3, 8091-8097.

16 Y. Oh, V.-D. Le, U. N. Maiti, J. O. Hwang, W. J. Park, J. Lim, K. E. Lee, Y.-S. Bae, Y.-H. Kim and S. O. Kim, ACS Nano, 2015, 9, 9148-9157.
17 G. P. Hao, W. C. Li, D. Qian and A. H. Lu, Adv. Mater., 2010, 22, 853-857.

18 M. Sevilla, P. Valle-Vigón and A. B. Fuertes, Adv. Funct. Mater., 2011, 21, 2781-2787.

19 J. Wang, A. Heerwig, M. R. Lohe, M. Oschatz, L. Borchardt and S. Kaskel, J. Mater. Chem., 2012, 22, 13911-13913.

20 Z. Tian, N. Fechler, M. Oschatz, T. Heil, J. Schmidt, S. Yuan and M. Antonietti, J. Mater. Chem. A, 2018, 6, 19013-19019.

21 Y. Zhao, X. Liu and Y. Han, RSC Adv., 2015, 5, 30310-30330.

22 X. Zhu, C. Tian, G. M. Veith, C. W. Abney, J. Dehaudt and S. Dai, J. Am. Chem. Soc., 2016, 138, 11497-11500.

23 Y. Zhao, K. X. Yao, B. Teng, T. Zhang and Y. Han, Energy Environ. Sci., 2013, 6, 3684-3692.

24 Y. Belmabkhout, V. Guillerm and M. Eddaoudi, Chem. Eng. J., 2016, 296, 386-397.

25 J. Liu, P. K. Thallapally, B. P. McGrail, D. R. Brown and J. Liu, Chem. Soc. Rev., 2012, 41, 2308-2322.

26 R. Luebke, J. F. Eubank, A. J. Cairns, Y. Belmabkhout, L. Wojtas and M. Eddaoudi, Chem. Commun., 2012, 48, 1455-1457.

27 K. Sumida, D. L. Rogow, J. A. Mason, T. M. McDonald, E. D. Bloch, Z. R. Herm, T. H. Bae and J. R. Long, Chem. Rev., 2012, 112, 724-781.

28 Y. K. Kim, G. M. Kim and J. W. Lee, J. Mater. Chem. A, 2015, 3, 10919-10927.

29 T. M. McDonald, J. A. Mason, X. Kong, E. D. Bloch, D. Gygi, A. Dani, V. Crocella, F. Giordanino, S. O. Odoh, W. S. Drisdell, B. Vlaisavljevich, A. L. Dzubak, R. Poloni, S. K. Schnell, N. Planas, K. Lee, T. Pascal, L. F. Wan, D. Prendergast, J. B. Neaton, B. Smit, J. B. Kortright, L. Gagliardi, S. Bordiga, J. A. Reimer and J. R. Long, Nature, 2015, 519, 303-308.

30 X. Ren, H. Li, J. Chen, L. Wei, A. Modak, H. Yang and Q. Yang, Carbon, 2017, 114, 473-481.

31 J. W. To, J. He, J. Mei, R. Haghpanah, Z. Chen, T. Kurosawa, S. Chen, W. G. Bae, L. Pan, J. B. Tok, J. Wilcox and Z. Bao, J. Am. Chem. Soc., 2016, 138, 1001-1009.

32 R. Vaidhyanathan, S. S. Iremonger, G. K. H. Shimizu, P. G. Boyd, S. Alavi and T. K. Woo, Science, 2010, 330, 650653.

33 Y. Zhao, X. Liu, K. X. Yao, L. Zhao and Y. Han, Chem. Mater., 2012, 24, 4725-4734.

34 J. R. Li, J. Yu, W. Lu, L. B. Sun, J. Sculley, P. B. Balbuena and H. C. Zhou, Nat. Commun., 2013, 4, 1538.

35 N. P. Wickramaratne and M. Jaroniec, J. Mater. Chem. A, 2013, 1, 112-116.

36 G. Zhu, R. G. Jensen, R. B. Hallick and G. F. Wildner, Plant Physiol., 1992, 98, 764-768.

37 A. Silvestre-Albero, S. Rico-Francés, F. Rodríguez-Reinoso, A. M. Kern, M. Klumpp, B. J. M. Etzold and J. SilvestreAlbero, Carbon, 2013, 59, 221-228.

38 Q. Liu, A. Mace, Z. Bacsik, J. Sun, A. Laaksonen and N. Hedin, Chem. Commun., 2010, 46, 4502-4504.

39 P. Nugent, Y. Belmabkhout, S. D. Burd, A. J. Cairns, R. Luebke, K. Forrest, T. Pham, S. Ma, B. Space, L. Wojtas, M. Eddaoudi and M. J. Zaworotko, Nature, 2013, 495, 80-84. 
40 O. Shekhah, Y. Belmabkhout, Z. Chen, V. Guillerm, A. Cairns, K. Adil and M. Eddaoudi, Nat. Commun., 2014, 5, 4228.

41 R. Walczak, B. Kurpil, A. Savateev, T. Heil, J. Schmidt, Q. Qin, M. Antonietti and M. Oschatz, Angew. Chem., Int. Ed., 2018, 57, 10765-10770.

42 B. Kurpil, A. Savateev, V. Papaefthimiou, S. Zafeiratos, T. Heil, S. Özenler, D. Dontsova and M. Antonietti, Appl. Catal., B, 2017, 217, 622-628.

43 A. L. Myers and J. M. Prausnitz, AIChE J., 1965, 11, 121-127.

44 M. Oschatz, M. Leistner, W. Nickel and S. Kaskel, Langmuir, 2015, 31, 4040-4047.

45 H. T. Chifotides, B. L. Schottel and K. R. Dunbar, Angew. Chem., Int. Ed., 2010, 49, 7202-7207.
46 S. Kirkpatrick, C. D. Gelatt and M. P. Vecchi, Science, 1983, 220, 671-680.

47 R. Car and M. Parrinello, Phys. Rev. Lett., 1985, 55, 24712474 .

48 T. D. Kühne, M. Krack, F. R. Mohamed and M. Parrinello, Phys. Rev. Lett., 2007, 98, 066401.

49 T. D. Kühne, Wiley Interdiscip. Rev.: Comput. Mol. Sci., 2014, 4, 391-406.

50 R. Srivastava, M. Choi and R. Ryoo, Chem. Commun., 2006, 4489-4491.

51 D. Verboekend and J. Pérez-Ramírez, Catal. Sci. Technol., 2011, 1, 879-890. 